\title{
A modelling system for the exhaust emissions of marine traffic and its application in the Baltic Sea area
}

\author{
J.-P. Jalkanen ${ }^{1}$, A. Brink ${ }^{2}$, J. Kalli ${ }^{3}$, H. Pettersson ${ }^{1}$, J. Kukkonen ${ }^{1}$, and T. Stipa ${ }^{1}$ \\ ${ }^{1}$ Finnish Meteorological Institute, P.O. Box 503, 00101 Helsinki, Finland \\ 2 Åbo Akademi, Process Chemistry Center (CMC), Tuomiokirkontori 3, 20500 Turku, Finland \\ ${ }^{3}$ University of Turku, Centre for Maritime Studies, P.O. Box 181, 28101 Pori, Finland
}

Received: 15 May 2009 - Published in Atmos. Chem. Phys. Discuss.: 17 July 2009

Revised: 27 November 2009 - Accepted: 27 November 2009 - Published: 7 December 2009

\begin{abstract}
A method is presented for the evaluation of the exhaust emissions of marine traffic, based on the messages provided by the Automatic Identification System (AIS), which enable the identification and location determination of ships. The use of the AIS data facilitates the positioning of ship emissions with a high spatial resolution, which is limited only by the inaccuracies of the Global Positioning System (typically a few metres) that is used in vessel navigation. The emissions are computed based on the relationship of the instantaneous speed to the design speed, and the detailed technical information of the engines of the ships. The modelling of emissions is also based on a few basic principles of ship design, including the modelling of the propelling power of each vessel in terms of its speed. We have investigated the effect of waves on the consumption of fuel, and on the emissions to the atmosphere. The predictions of fuel consumption were compared with the actual values obtained from the shipowners. For a Roll on - Roll off cargo/passenger ship (RoPax), the predicted and reported values of annual fuel consumption agreed within an accuracy of $6 \%$. According to the data analysis and model computations, the emissions of $\mathrm{NO}_{\mathrm{x}}, \mathrm{SO}_{\mathrm{x}}$ and $\mathrm{CO}_{2}$ originating from ships in the Baltic Sea during the full calendar year of 2007 were in total $400 \mathrm{kt}$, $138 \mathrm{kt}$ and $19 \mathrm{Mt}$, respectively. A breakdown of emissions by flag state, the type of ship and the year of construction is also presented. The modelling system can be used as a decision support tool in the case of issues concerning, e.g., the health effects caused by shipping emissions or the construction of emission-based fairway dues systems or emissions trading. The computation of emissions can be automated, which will
\end{abstract}

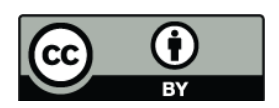

Correspondence to: J.-P. Jalkanen (jukka-pekka.jalkanen@fmi.fi) save resources in constructing emission inventories. Both the methodologies and the emission computation program can be applied in any sea region in the world, provided that the AIS data from that specific region are available.

\section{Introduction}

Problems in air quality related to emissions from shipping have been reported globally (Corbett et al, 2007; Dalsøren et al., 2007; Endresen et al., 2003; Corbett et al., 1999; Capaldo et al., 1999), regionally (Wang et al., 2007; Gergakaki et al., 2005; Davis et al., 2001; Delft, 2006; Lloyds, 1999; ENTEC, 2005; Kesgin et al., 2001, ENTEC, 2002) and for large port areas (Yang et al., 2007; Starcrest, 2008; Dong et al., 2002; Isaksson et al., 2001). In addition to the influence of collisions and groundings, the adverse health and environmental effects of marine traffic caused by its atmospheric emissions can be substantial. Ship traffic has been recently estimated to contribute to approximately 60000 premature deaths each year globally (Corbett et al., 2007). The highest mortality rates were reported around the English Channel, on the eastern coast of the USA and in Southeast Asia; these were proposed to be caused by an increased number of cardiopulmonary cases due to increased concentrations of ultrafine particulate matter. One of the key components of the particulate matter, sulphates, can be effectively reduced by using low-sulphur fuel in marine diesel engines. Within the International Maritime Organization (IMO) there is already an agreed process for the long-term reduction of the sulphur content of marine fuel (IMO, 2008).

The Baltic Sea is a busy area for short-sea marine traffic. It was also the first control area for $\mathrm{SO}_{\mathrm{x}}$ emissions

Published by Copernicus Publications on behalf of the European Geosciences Union. 
(SECA), with control legislation taking effect from 16 May 2006. Most of the existing methods to estimate emissions of ship traffic up to the present have relied on simplified information (Endresen et al., 2003, 2005, 2007; Dalsøren et al., 2007; Dentener et al., 2006) and are based on averages in terms of the number and size of vessels, the distances travelled between ports, engine power levels and/or the amounts of fuel. Global inventories of ship emissions have been presented, e.g., by Endresen et al. (2003) and Wang et al.(2008), but their application to the Baltic Sea has lead to an underestimation in the air emissions due to shipping, mainly due to an insufficient description of the short-sea traffic (Wang et al., 2008). The Baltic Sea is defined here as the area including both the Baltic Sea and the entrance to the Baltic Sea that is bounded by the parallel of the Skaw in the Skagerrak $(57.74 \mathrm{~N}, 10.6325 \mathrm{E})$.

The IMO has set new emission limits for $\mathrm{NO}_{\mathrm{x}}$ and $\mathrm{SO}_{\mathrm{x}}$ in its upcoming revision of MARPOL Annex VI (IMO, 2008), which allows for the setting of regional $\mathrm{NO}_{\mathrm{x}}$ emission caps, and aims at switching to sulphur-free fuel globally by the end of 2020 .

In order to reduce the risk of collision between ships, the IMO has stipulated that a navigational aid called the Automatic Identification System (AIS) is to be used in ships globally (IMO, 2000) as a tool for the short-range identification and tracking of ships. Based on the analysis of this work, there are more than 2000 vessels anchored or en route to different harbours at any given time, and about 3500-5000 different vessels are in operation in the Baltic Sea area every month. These values are based on the unique Mobile Maritime Service Identity (MMSI) numbers sent in the AIS messages; these include only the vessels with an active AIS transmitter onboard. In addition, a substantial number of small $(<300 \mathrm{GT})$ vessels exist, which are not required to use AIS; for such vessels the use of AIS is voluntary.

AIS is based on VHF radio transmissions; the typical maximum range of an AIS base station is therefore from 50 to $90 \mathrm{~km}$, depending on the height of the antenna and atmospheric conditions. A complete coverage of a shore based system can therefore only be expected in areas where the AIS base station network is sufficiently closely-spaced, such as, e.g., in the Baltic Sea area. If applied globally, a satellite based AIS network would have to be used. The use of AIS is mandatory for all larger ships, exceeding the 300 gross tonnage limit, and there is no bias towards data from specific ship types. The latter may be the case for ICOADS (International Comprehensive Ocean-Atmosphere Data Set) and AMVER (Automated Mutual-Assistance VEssel Rescue system) (Endresen et al., 2003); these may lead to a biased evaluation of emissions that can emphasize, for example, the influence of cargo ships. Both ICOADS and AMVER may serve well as data sources for global ship emission assessments, but AIS information can be used to provide more accurate assessments in specific regions.
Up to date, harbour arrivals and departure data, and the locations of main shipping lanes have mostly been used in deciding where ships sail (Bewersdorff et al., 2008; Georgakaki et al., 2005). However, significant uncertainties exist in determining the time spent at sea, engine load profiles used and emission factors applied. The use of AIS data can improve the emission estimates by providing information of changes in speed during voyages and the actual position of vessels. The ENTEC ship emission study (ENTEC, 2002) was based on a period of four months of vessel movements in the EU area, and extrapolated annual emissions were presented. In the ENTEC study, the treatment of short-sea traffic was laborious, as the data source listed only one port of call per day and per vessel, even if a vessel was engaged in regular traffic between two harbours several times a day. A substitutive method for ferries in the EU area was used in the ENTEC study, which was based on estimated number of port calls during each day, which could lead to significant inaccuracies, especially for relatively short-distance sea routes such as the traffic across the Gulf of Finland between Helsinki and Tallinn for which the passenger traffic is intensive.

Accounting fully for short-sea traffic, the emission model described in this paper, STEAM (Ship Traffic Emission Assessment Model), allows for the computation of emissions with a fine temporal resolution; the position of the ships are updated at one second intervals. However, for most applications, averaging periods of minutes or hours are used. As the estimated engine power levels are based on a few basic principles of ship design, the use of average ship properties is restricted only to cases where the ship data is insufficient. Previous studies have listed several methodological uncertainties related to the location of emissions (Corbett et al., 2003; Wang et al., 2008; Georgakaki et al., 2005). Furthermore, previous studies have mostly, although not completely, neglected the effects of emission abatement techniques, the changes in ship speed and the true position of the ships and the consequent effects of these factors on emissions. There is an evident need for an assessment system that can more accurately describe the behaviour of ships and both the temporal and spatial distribution of emissions (Lauer et al., 2007; Richter et al., 2004).

This study is, to our knowledge, the first attempt to model ship emissions in international sea areas using the AIS data as a starting point. The objective of this study is to highlight the improvement in the accuracy and reliability of ship emission inventories that can be obtained by using the more accurate ship movements contained in AIS position reports. In addition, significant improvements can be achieved in information regarding, for example, daily traffic numbers, flag state and ship types. Some selected results regarding the marine traffic in the Baltic Sea are also presented. In Sect. 2.1 and 2.2 the model input data is described and a general procedure for AIS-based emission estimates is presented in Sect. 2.3 followed by the details of the algorithm for power prediction of individual ships and estimates of the effects of waves. 
Table 1. The input data of the STEAM model regarding the properties of ships. The notation: MMSI= Mobile Maritime Service Identity, $\mathrm{ME}=$ Main engine, $\mathrm{AE}=$ Auxiliary engine, $\mathrm{rpm}=$ crankshaft revolutions per minute, $\mathrm{SFOC}=$ Specific Fuel Oil Consumption, Measured $\mathrm{EF}=$ Experimental value for emission factors of $\mathrm{NO}_{\mathrm{X}}, \mathrm{SO}_{\mathrm{X}}, \mathrm{CO}$ and $\mathrm{PM}$.

\begin{tabular}{llll}
\hline Identification & Physical properties & Main engine properties & Auxiliary engine properties \\
\hline Ship name & Length & ME, Fuel sulphur content & AE, installed kW \\
IMO registry number & Breadth & ME, abatement technique & Number of AE \\
MMSI code & Draught & ME, SFOC & AE, Fuel type \\
Ship type & Build year & ME, design & AE, Fuel sulphur content \\
Gross tonnage & Design speed & ME, model & AE, SFOC \\
Deadweight tonnage & Number of cabins & ME, stroke type & AE, abatement technique \\
& Hull type & ME, rpm & \\
& & Number of ME & \\
& & ME, installed kW & \\
& & ME, Fuel type1 & \\
& & ME, Fuel type2 & \\
& Measured EFs & \\
\hline
\end{tabular}

In Section 3 some selected results are shown followed by conclusions (Sect. 4). The scientific aim was to develop a methodology that can make optimum use of the more accurate information of ship movements given in AIS position reports. We have designed the computational system to be sufficiently flexible and versatile, in order to be potentially applicable globally in the future.

\section{Material and methods}

\subsection{The input data of the STEAM model regarding the properties of ships}

The primary source of ship data for the STEAM model is the internal database of technical information for more than 20000 vessels, which is crucial to be able to predict reliably the emissions. The structure of the database is outlined in Table 1. The database is premised on the information of the Lloyds ship register, and complemented with information from engine manufacturers, local authorities and ship owners. This information usually consists of experimentally determined emission factors, installed abatement techniques (Which technique is applied and on which engines), shaft generators, specific fuel oil consumption, and fuel type and sulphur content of fuel for main and auxiliary engines. The stack height data is not currently included as this information was more difficult to obtain.

In addition to the database fields mentioned in Table 1, the database contains measured emission factors, if these are known.

Although the database contains information regarding the hull structure, all vessels are currently handled as single hull and single propeller type vessels. The effect of abatement
Table 2. The various abatement techniques and their evaluated emission reduction efficiencies in case of $\mathrm{NO}_{\mathrm{x}}$ and $\mathrm{SO}_{\mathrm{x}}$ In addition, the model includes treatments of particulate filters and oxidation reactor; these affect the emissions of particulate matter and CO (ENTEC, 2005; Wahlström et al., 2006; Lövblad et al., 2006; DeMers et al., 2000).

\begin{tabular}{lll}
\hline Abatement technique & $\mathrm{NO}_{\mathrm{x}}$ reduction & $\mathrm{SO}_{\mathrm{x}}$ reduction \\
\hline In engine modifications & $-20 \%$ & \\
Exhaust gas recirculation & $-35 \%$ & \\
Direct Water Injection & $-50 \%$ & \\
Humid Air Motor & $-70 \%$ & \\
Selective Catalytic Reduction & $-90 \%$ & $-95 \%$ \\
Sea Water Scrubber & & \\
Fuel Emulsifier & $-10 \%$ & \\
Wetpac & $-50 \%$ & \\
\hline
\end{tabular}

techniques has been taken into account by applying reduction factors for emissions according to Table 2.

It is possible to decrease the amount of $\mathrm{NO}_{\mathrm{x}}$ and $\mathrm{SO}_{\mathrm{x}}$ by technical measures, but curbing $\mathrm{CO}_{2}$ emissions is more difficult. Currently ten abatement techniques have been modelled and emission reduction factors are assigned for each technique (ENTEC, 2005; Wahlström et al., 2006; Lövblad et al., 2006; DeMers et al., 2000). If emission certificates have been granted for a ship, the certified emission factors are used. Separate emission factors and specific fuel consumption values are assigned for main and auxiliary engines. The current procedure for determining emissions from a ship relies on the use of the detailed technical data of the engines. If such data are missing, the average values for that specific ship type are used. 
The emission inventories do not currently include the particulate matter (PM) emitted by ships. This is mainly due (i) to insufficient data regarding the ash content and fuel types that are specific to those of the main and auxiliary engines in use in the Baltic Sea area, and (ii) to the uncertainties regarding the chemical composition and other properties of the emitted PM. The emissions of CO and PM are also highly dependent on engine load; a method of estimating the engine loads of ships, which have multiple main engines, has not currently been implemented.

\subsection{Other input data of the STEAM model}

The vessel movement data has been extracted from the Helsinki Commission (HELCOM) AIS data center; it consists of data received by the AIS base station networks of Finland, Sweden, Denmark, Germany, Poland, Latvia, Lithuania, Estonia and the Russian Federation surrounding the Baltic Sea. AIS data results in an extensive data flow yielding hundreds of thousands of position reports per ship every year. The data can be freely received with a VHF antenna, since it is not encrypted. However, the use of a national AIS base station network data may require an agreement with the national maritime administration. The use of AIS for extensive sea regions may involve negotiations with authorities in many countries, but the data can also be accessed commercially. Global coverage can only be expected from commercial data providers utilizing a satellite-based AIS network.

The technical details used in this study are taken mainly from the Lloyds register, but they are complemented with data from various authorities, ship owners and other public sources. Fuel types, specific consumption, fuel sulphur content and measured emissions are taken into account, if the shipowner has made this data available. This information has mostly been granted by the Finnish and Estonian ship owners and the maritime authorities of the Baltic Sea countries, but as much experimental data is included as possible. The specific fuel oil consumption of $200 \mathrm{~g} / \mathrm{kWh}$ is used for all engines as a default value and emissions of $\mathrm{CO}_{2}$ and $\mathrm{SO}_{\mathrm{x}}$ are calculated from the fuel consumption and sulphur content, respectively.

\subsection{Description of the model}

The main algorithms of the STEAM model are described schematically in Fig. 1. The program first decodes the received AIS transmissions and checks whether any new ships are encountered. The IMO registry number in the AIS messages is compared against the internal ship database. If the IMO registry number of the ship cannot be found in the database, the Lloyds ship register (Lloyds, 2009) is queried for the technical details. The ship type is determined based on the database entry of the IMO registry number, or if this number is missing, on AIS data. The instantaneous speed and the vessel location are extracted from the AIS data. If a

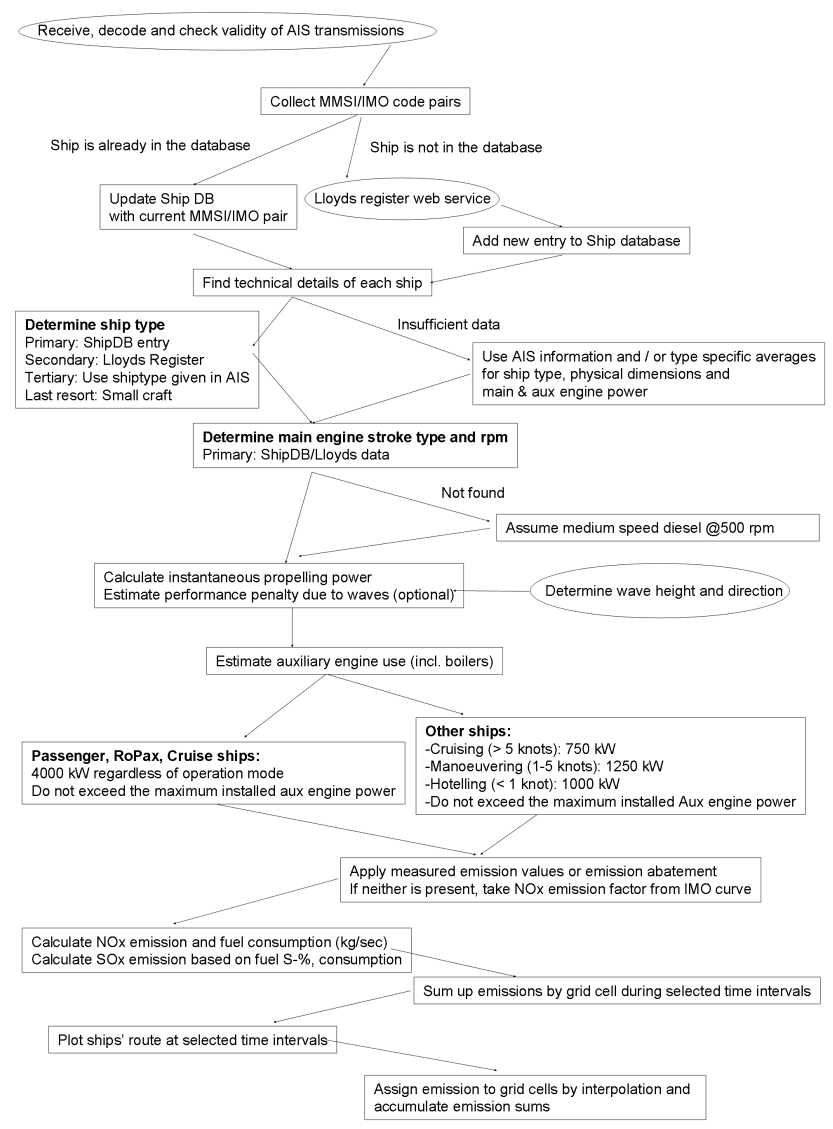

Fig. 1. A schematic presentation of the main algorithms of the STEAM model. The lines indicate the flow of information, from top to bottom. Input data has been presented with ellipsoids. RoPax $=$ RoRo/Passenger ship, MMSI $=$ Maritime Mobile Service Identity.

vessel cannot be identified at all, it is assumed to be a small craft and average values for tugboats are used (GT 620, main engine $2380 \mathrm{~kW}$ ). The program uses crankshaft rpm (rpm, revolutions per minute) data to assign $\mathrm{NO}_{\mathrm{x}}$ emission factors, which are based on the following (IMO, 1997):

$$
\begin{aligned}
& \text { Emission_factor } \\
& (\mathrm{g} / \mathrm{kWh})
\end{aligned}=\left\{\begin{array}{l}
17, \text { for engines less than 130rpm } \\
45.0 * \mathrm{n}^{-0.2} \\
\text { for engines } 130<\mathrm{n}<2000 \\
\mathrm{n}=\text { engine rpm } \\
9.8, \text { for engines over } 2000 \mathrm{rpm}
\end{array}\right.
$$

It is assumed that the $\mathrm{NO}_{\mathrm{x}}$ emission factors of all engines, regardless of their year of construction, can be computed based on the IMO curve and are independent of the fuel consumption. However, the predictions of the emissions of $\mathrm{SO}_{\mathrm{x}}$ and $\mathrm{CO}_{2}$ are based on engine-specific fuel consumption, see supplementary material I http://www.atmos-chem-phys. net/9/9209/2009/acp-9-9209-2009-supplement.pdf for a detailed description. 
If engine data is unavailable, the ship is assumed to use a $500 \mathrm{rpm}$ medium speed diesel engine by default. Propelling power is then evaluated, and the user has the option of including the effects of waves in the emission estimates. This will result in an increased power demand, which depends on wave height and contact angle with the ship. The auxiliary engine profile is determined based on the ship type and operating mode. After main and auxiliary engine power levels have been estimated, emission factors are applied based either on directly the IMO $\mathrm{NO}_{\mathrm{x}}$ curve or using the information on measured emissions levels and installed abatement techniques. Clearly, there are uncertainties regarding the emission factors of $\mathrm{NO}_{\mathrm{x}}$. To mention one specific example, the emission factors of two selected RoRo vessels have been experimentally determined as 13.0 and $13.5 \mathrm{~g} / \mathrm{kWh}$, while the emission factors based on Eq. (1) yielded the values of $12.98 \mathrm{~g} / \mathrm{kWh}$ in both cases. The emission factors change as a function of engine load and may be larger for engines operating at low loads, which is the case especially during harbor manouvers. The change of emission factors as a function of engine load has not currently been taken into account in the model.

The process presented in Fig. 1 is repeated for all the ships and emissions. To ensure the continuity of the data, the route and fuel consumption values are linearly interpolated based on the received AIS signals. Interpolation is not done, if the time difference between two position reports is longer than $72 \mathrm{~h}$. If the time between consecutive position reports is longer than this limit value, no emission is predicted to occur during the data gap. The position of the vessel and its emissions are calculated each second between the two known locations, after a consistency check. During the consistency check great circle distance and average speed of the vessel are calculated to determine if the vessel can really travel the distance between the two position reports. Certainly, if the technical data for a ship is outdated or inaccurate, or significant gaps in the AIS data are encountered, the accuracy of the predictions deteriorates.

The STEAM model could be applied globally, if global coverage of AIS can be achieved. However, this is not possible if solely shore based AIS base stations are used, as the signal access range of an AIS base station is approximately $90 \mathrm{~km}$. Because the AIS system is based on the use of VHF radio transmissions, the curvature of the Earth hinders the receiving of data from sufficiently distant stations. Shore based AIS network can fully cover the Baltic Sea, but extensive sea areas cannot be covered using only shore based base stations. For this purpose, a satellite based AIS network is available commercially that provides a complete global coverage.

\subsection{Engine power estimates for individual ships}

Once the ship has been identified and its location has been determined, detailed and up-to-date technical information about each vessel is used, especially regarding the main and auxiliary engines, boilers, generators and design speed.
When the speed and technical data of the vessel are known, an estimate of its level of main and auxiliary engine use is computed based on the functional dependence of the instantaneous speed and the design speed; the fuel consumption and exhaust emissions of the vessel are then calculated. These result in a ship-specific fuel and emission inventory.

The instantaneous power $P$ is evaluated as a function of the velocity of the ship $V$ (ITTC, 1999):

$$
P_{\text {transient }}=(C F+C R+C A+C A A)\left(\frac{1}{2} V^{3} S\right) \frac{1}{\varepsilon_{0}}
$$

where $C F, C R, C A$ and $C A A$ are the frictional resistance, residual resistance, appendage resistance and air resistance, respectively; $\varepsilon_{0}$ is the propulsive coefficient and $S$ the wet surface of the ship. All values in Eq. (2) are in $S I$ units. Normally the maximum power $P_{\max }$ is $80 \%$ of the total installed main engine power, which is assumed to represent the Maximum Continuous Rating (MCR) of the engine, when the vessel travels at its design speed. In this study, a safety margin of $0.257 \mathrm{~m} / \mathrm{s}(0.5 \mathrm{knot})$ in design speed is used for all ships; the propelling power will suffice to move the ship at its design speed plus the safety margin when $P=P_{\max }$. For some vessels the instantaneous speed transmitted over AIS system exceeded the design speed entry in Lloyds ship register. To cope with this uncertainty, a small safety marginal of $0.257 \mathrm{~m} / \mathrm{s}(0.5 \mathrm{knots})$ was used.

Correlations describing these parameters $(C F, C R, C A$, $C A A$ and $\varepsilon_{0}$ ) can be found in the literature, but they are typically functions of hull-specific parameters that cannot be found in available databases. A straightforward solution to this problem is to simplify Eq. (2) by assuming that $C F, C R$, $C A, C A A, S$ and $\varepsilon_{0}$ are ship-specific constants. Then Eq. (2) can in that case be written simply as (Eq. 3):

$$
P_{\text {transient }}=\frac{k V_{\text {transient }}^{3}}{0.514^{3}}
$$

where $k$ is defined as

$$
k=0.514^{3} * \frac{\varepsilon_{p} * P_{\text {installed }}}{\left(V_{\text {design }}+V_{\text {safety }}\right)^{3}}
$$

where $\mathrm{P}_{\text {installed }}$ is the total installed power $(\mathrm{kW})$ of the main engines, $\varepsilon_{p}$ is the main engine load at Maximum Continuous Rating of the main engines and and $V_{\text {design }}$ and $V_{\text {safety }}$ are the design speed and the safety margin (in $\mathrm{m} / \mathrm{s}$ ), respectively.

The problem is then reduced to finding the shipspecific parameter $k$ that describes the quantity $(C F+C R+C A+C A A) * 1 / 2 * \mathrm{~S}^{*} \varepsilon^{-1}$. In Eq. (4), the $\varepsilon_{p}$ is assumed to be equal to 0.8 , as the maximum continuous rating of the engine is thought as $80 \%$ of the total installed main engine power $(\mathrm{kW})$. The main limitation of this approach is related with the assumption that $\mathrm{CF}$ is a constant. The existing correlations for CF typically are functions of the velocity. The current approach completely neglects the 
speed dependency of frictional resitance, but the overall effect is likely to be small.

Different ship types have different ways of using their engines, especially during harbour visits; they may use different fuel on the open sea and in harbours. The electricity requirements vary depending on the type of the ship. The model described in this paper uses different auxiliary engine profiles for various vessel types. For instance, the energy demand of a large cruise ship with more than a thousand airconditioned cabins is considerably different from that of a bulk cargo carrier. Auxiliary engine use plays a predominant role in modelling the emissions in harbour areas, because auxiliary engines are used to generate electricity during stays in harbours, while main engines do not contribute to harbour emissions significantly during hotelling.

Current estimates for auxiliary engine use are based on ship-type specific profiles, depend on the operating mode of the ship and employ the following rules: 1) Passenger, RoPax and cruise ships use $4000 \mathrm{~kW}$ of auxiliary engine power regardless of the operation mode. This includes boilers, if any. 2) All other types of ships use $750 \mathrm{~kW}$ of auxiliary engine power during cruise, $1250 \mathrm{~kW}$ during port manoeuvers and $1000 \mathrm{~kW}$ during hotelling. 3) No more than $20 \%$ of the installed main engine power is allowed for auxiliary engine output. This restriction applies to ships for which auxiliary engine data is unavailable, constituting approximately $15 \%$ of the $\sim 20000$ ships in the internal database. 4) Predicted instantaneous auxiliary engine usage cannot exceed maximum installed auxiliary engine power. The operating modes are determined by the speed of the vessel.

The use of boilers has a strong seasonal dependence; it has a minimum in summer months and a maximum during the winter period. The reason is probably the energy required by heating service water; less energy is required during summer due to higher ambient temperatures. Exactly the opposite seems to be valid for auxiliary engines as the fuel consumption of the auxiliary engines in the investigated RoPax vessels has a maximum in summer and a minimum in winter, most probably due to the air conditioning required to cool the passenger areas in summer. These two factors have therefore a counteracting influence on the seasonal variation of the fuel consumption. The assumption of a constant value for auxiliary engine use and boilers is therefore reasonable, but could be refined in the future.

\subsubsection{The experimental data used for the evaluation of the STEAM model}

The best method of evaluating the predictions of emissions would be a direct comparison with the measurements of ship exhausts. However, this would require an extensive amount of measurements for different ship types in various operating conditions. Instead, we have compared the predicted and reported fuel consumptions.
Fuel is a major item of expenditure; every commercially operated ship therefore archives at least monthly records. The fuel consumption and emissions to the atmosphere of any ship are computed as a function of instantaneous engine power. Obtaining engine-specific fuel consumption data for quality control purposes requires a continuous cooperation with the shipowners.

The data collected in this study from interviews with Finnish shipowners consist of the annual fuel consumption of six RoPax vessels, ranging from hourly to monthly reports of the fuel consumption. The fuel consumption of main and auxiliary engines and boilers are reported separately; this facilitates the adjustments of ship-specific power profiles. The measured emissions of specific ships are used in the model calculations, if the shipowner has made this information available. However, currently such cases constitute less than $1 \%$ of all the ships in the Baltic Sea area.

\subsubsection{Effects of waves}

Waves increase the fuel consumption of ships by affecting the ability of ships to move through water. The model takes the effects of waves into account; the model predicts additional power requirements in high sea states. The hourly significant wave heights and the mean wave direction data are obtained from the WAve Model (WAM) (Komen et al., 1994) and the increased power demand is subsequently modelled by the STEAM model, according to Townsin et al. (1993). The grid resolutions of the WAM model were $0.2^{\circ}$ lon by $0.1^{\circ}$ lat; the model used as input data the wind predicted by the numerical weather prediction model HIRLAM.

The implementation and performance of the WAM model in the Baltic Sea is described in Tuomi (2008). Besides the sea state, the additional power requirement depends on parameters describing the wet surface and the threedimensional structure of the hull (these are different, for example, for oil tankers and passenger ships), and the contact angle between the hull and waves. The wet surface is defined as the area of the hull that is directly in contact with the water, contributing to the frictional resistance.

The directional part of the so-called speed penalty is (modified based on Townsin et al., 1993)

$\mu=\left\{\begin{array}{l}1.0, \theta \leq 30^{\circ} \\ \frac{1.7-0.03(B N-4)^{2}}{2}, 30<\theta \leq 60 \\ \frac{0.9-0.03(B N-6)^{2}}{2}, 60<\theta \leq 150 \\ \frac{1.7-0.03(B N-8)^{2}}{2}, \theta>150\end{array}\right.$

where $\theta$ is the contact angle between the wave direction and the ship (in degrees) and $\mathrm{BN}$ is the effective Beaufort number (dimensionless). The evaluation of the increased power demand is dependent on $\mathrm{BN}$; hence, the modelled significant wave height obtained from the WAM model for fullydeveloped waves needs to be evaluated in terms of the BN.

Equation (5) is in a slightly modified form compared with the original equation presented by Townsin et al. (1993), as 


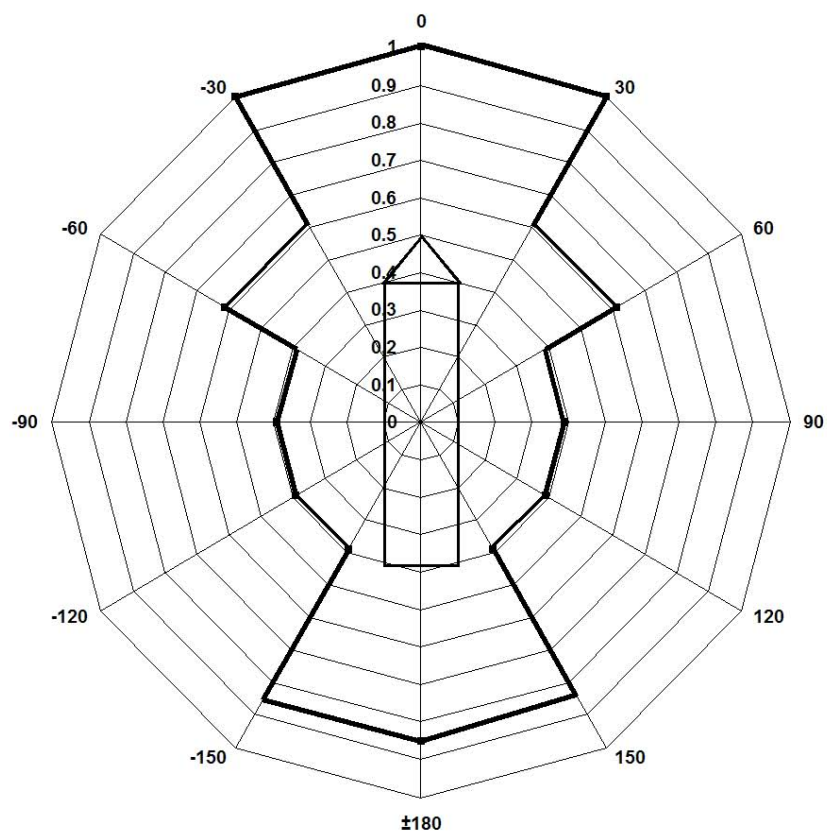

Fig. 2. The numerical values of the directional part of the wave speed penalty for Beaufort number 8 . The contact angle values range from 0 to \pm 180 degrees and the numerical values for the directional part of the speed penalty are presented in relative units that range up to unity.

the original equation resulted in a non-physical behaviour at high BN's. For all the other values except for very high BN's, the equations in this study and those by Townsin et al. (1993) provide almost identical values. The speed penalty applied to any ship in the present study is restricted to a maximum reduction of $50 \%$, which would require a significant wave height of $5 \mathrm{~m}$ for oil tankers and $11 \mathrm{~m}$ for other ships. The relative speed reduction in Townsin et al. (1993) was restricted to a maximum of $25 \%$ and the volume of displacement of the smallest vessel was over $50000 \mathrm{~m}^{3}$. As the relative speed reduction is dependent on the vessel size, and very small vessels are equipped with AIS too, the use of a very high speed penalty would clearly be an extrapolation of the original results.

The directional part of the speed penalty for a cargo ship in case of an effective Beaufort number (BN) equal to 8 is presented in Fig. 2. Speed penalty is applied to its maximum extent, when the contact angle with the hull is small (from 0 to \pm 30 degrees), and the ship is heading directly against the waves. The directional part decreases, as the contact angle increases; however, it increases again, as the contact angle approaches 180 degrees, i.e., for the waves encountering the ship directly from behind. The situation selected in Fig. 2 corresponds to a record-high significant wave height $(7.7 \mathrm{~m})$ on 22 December 2004 near the island of Gotland, Sweden.

The relations between BN, the corresponding wind speed ranges and the significant wave heights given by Townsin et al. (1993) are presented in Table 3, as well as the values for fully-developed waves predicted by the growth curves of Kahma (1986). The lower value of Kahma (1986) was used in this study. Based on the values in Table 3, an empirical expression was derived for the dependence of the effective $\mathrm{BN}$ on the significant wave height:

$\mathrm{BN}=4.21794 * \mathrm{Hs}^{0.31}$

where Hs is the significant wave height (m). The performance penalties for tankers and other ships are (Townsin et al., 1993)

$\frac{\Delta V}{V} 100 \%=C * \mathrm{BN}+\frac{\mathrm{BN}^{6.5}}{2.7 \nabla^{2 / 3}}$ for oil tankers,

$\frac{\Delta V}{V} 100 \%=C * \mathrm{BN}+\frac{\mathrm{BN}^{6.5}}{22 \nabla^{2 / 3}}$ for other ships,

where $\Delta V / V$ is the the speed penalty, i.e., a relative decrease of the speed of the ship $V$ (percent), $\nabla$ is the displacement volume of the vessel $\left(\mathrm{m}^{3}\right)$ and $\mathrm{C}$ is a dimensionless parameter; its value is 0.5 for tankers and 0.7 for other ships. The difference between laden tankers and those carrying ballast cargos was not taken into account, since the effect is small. The performance penalty is given separately for oil tankers and for other ships, due to the shape differences in hull crosssection.

The increase in the required engine power is obtained by multiplying Eq. (7a-b) with the appropriate $\mu$ from Eq. (5).

$V_{\text {effective }}=\left(1+\mu * \frac{\Delta V}{V}\right) * V_{\text {inst }}$

Where $V_{\text {inst }}$ is an instantaneous velocity, derived based on two consequtive GPS observations.

The effect of waves is taken into account by computing a speed penalty (percent) in addition to $V_{\text {inst }}$, see Eq. (8). The resulting effective speed $V_{\text {effective }}$ is then used instead of the speed entry reported in the AIS messages (Eq. 3) .

\section{Results and discussion}

Real-time reception of the AIS data enables the real-time tracking of ship emissions, but significant amounts of data need to be analyzed. For example, the AIS position reports of the ships in the Baltic Sea area in 2007 consist of over 210 million individual messages. Counting the number of received AIS messages each hour revealed that in 2007 there were $146 \mathrm{~h}$ with no data, which corresponds to $98.3 \%$ availability for the AIS service. Our emission and fuel consumption values include all the ships in the Baltic Sea that have an active AIS transmitter, regardless of their destination or operating mode.

Grid resolutions of the order of a few hundreds of metres (or even less) can be used, which facilitates detailed studies 
Table 3. Correspondence of the significant wave height, the wind speed and the Beaufort number.

\begin{tabular}{lllll}
\hline $\begin{array}{l}\text { Effective Beaufort } \\
\text { number }\end{array}$ & $\begin{array}{l}\text { Wind speed range } 10 \mathrm{~m} \\
\text { above the surface }(\mathrm{m} / \mathrm{s})\end{array}$ & $\begin{array}{l}\text { Significant wave height } \\
\text { range }(\mathrm{m}) \text { (Kahma, 1986) }\end{array}$ & $\begin{array}{l}\text { Significant wave height }(\mathrm{m}) \\
\text { (Townsin et al., 1993) }\end{array}$ & $\begin{array}{l}\text { Significant wave height } \\
\text { used in this work }(\mathrm{m})\end{array}$ \\
\hline 0 & $0.0-0.2$ & 0.0 & - & 0.0 \\
1 & $0.3-1.5$ & $0.0-0.1$ & - & 0.0 \\
2 & $1.6-3.3$ & $0.1-0.3$ & - & 0.1 \\
3 & $3.4-5.4$ & $0.3-0.8$ & - & 0.3 \\
4 & $5.5-7.9$ & $0.8-1.7$ & - & 0.8 \\
5 & $8.0-10.7$ & $1.7-3.1$ & - & 1.7 \\
6 & $10.8-13.8$ & $3.2-5.2$ & 2.8 & 3.2 \\
7 & $13.9-17.1$ & $5.2-7.9$ & 4.8 & 5.2 \\
8 & $17.2-20.7$ & $8.0-11.6$ & 7.6 & 8.0 \\
9 & $20.8-24.4$ & $11.7-16.1$ & 11.3 & 11.7 \\
10 & $24.5-28.4$ & $16.2-21.8$ & 15.8 & 16.2 \\
11 & $28.5-32.6$ & $22.0-28.7$ & - & 22.0 \\
\hline
\end{tabular}

of emissions in port areas. In 2007, there were 9497 vessels carrying an active AIS transmitter in the Baltic Sea area. The primary means of identifying any ship is its IMO registry number. The secondary means of identification is the MMSI number (Maritime Mobile Service Identity) and the vessel name, which are used together. During the summer months the number of unidentified vessels is at a maximum. If the vessel cannot be identified at all, it is then assumed to be a small craft. These cases, at a maximum, represent $10 \%$ of the vessels in the Baltic Sea during June, July and August.

In its current state, the STEAM model assumes a default sulphur mass-percentage of 1.5 for the main engine, as required by the $\mathrm{SO}_{\mathrm{x}}$ Emission Control Area regulations of the IMO. For auxiliary engine fuel, a 0.5 mass-percentage of sulphur is assumed. If the shipowner has reported a lower sulphur content for the vessels, the lower values are used. A specific fuel oil consumption of $200 \mathrm{~g} / \mathrm{kWh}$ is used by default for all engines, although the structure of the STEAM model allows setting specific values for each of the engines, if these are known.

The contribution of vessels that are not equipped with the AIS system must be assessed using other methods since there is no centralized registry of vessels or vessel movements. For example, the annual contribution to $\mathrm{NO}_{\mathrm{x}}$ emissions from workboats, small fishing vessels and pleasure craft for Finland was estimated as 6 kilotons, concentrated around active fishing areas and pleasure craft harbours (Mäkelä, 2007). However, these numbers are not included in the estimate reported here, since we are not aware of any corresponding information source that would cover the whole of the Baltic Sea area.

We have evaluated quantitatively the effects of waves in Sect. 3.1. In the numerical results presented after that section, all emissions have been computed without the effects of waves, unless stated otherwise.

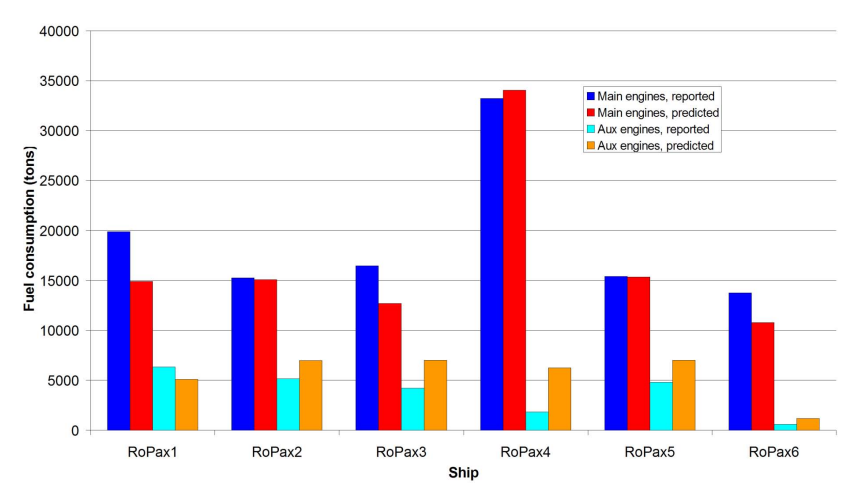

Fig. 3. Comparison of the predicted and reported annual fuel consumption of six RoPax ships in 2007. The predicted auxiliary engine consumption includes also the consumption of boilers.

\subsection{Comparison of predicted and reported fuel con- sumption, including the effects of waves}

The annual predictions for fuel consumption were compared with the actual consumption values obtained from the shipowners. A comparison presented here was performed for RoPax ships, as for this ship category the reported fuel consumption data were the most extensive.

A comparison between the predicted and reported annual fuel consumption of six RoPax ships ranging from 10000 to 60000 GT is presented in Fig. 3. The comparison in Fig. 3 presents only the predicted amount of fuel consumed in the Baltic Sea area, while the ship owner has reported all the fuel consumed by the vessel regardless whether it stays in the Baltic Sea or not (i.e., the consumption solely in the Baltic Sea has not been separately reported). The amount of the missing AIS data ranges in 2007 from $423 \mathrm{~h}$ for RoPax5 (i.e., $4.8 \%$ ) to $3632 \mathrm{~h}$ for RoPax6 (i.e., $41.4 \%$ ). 

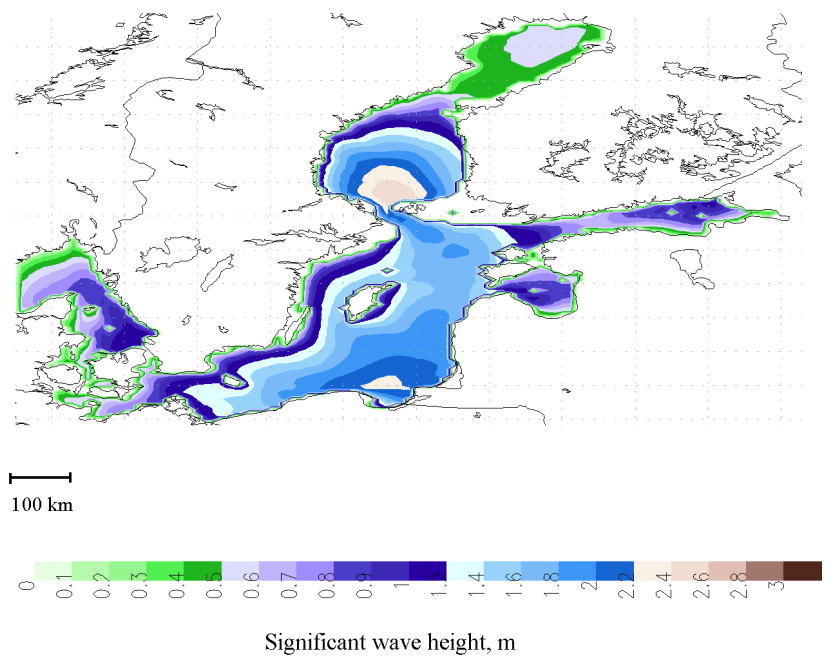

Fig. 4. An example of the significant wave height in the Baltic Sea at 22:00 UTC on 7 October 2007, as predicted by the WAM model.

The predicted fuel consumption of the main engines is well predicted for cases two, four and five, whereas for cases one, three and six, there are substantial differences between the predicted and reported values. For instance, the annual fuel consumption (neglecting wave effects) is within $5 \%$ of the reported values for the RoPax 5 ship in 2007. On the other hand, RoPax6 left the Baltic Sea area several times during 2007, which has decreased the reliability of the predicted fuel consumption.

If gaps in the AIS data are continuous and longer than $72 \mathrm{~h}$, neither emissions nor fuel consumption are interpolated over the gap. The large error in the predicted fuel consumption of RoPax 1 underlines the importance of up-to-date technical data. In this case, the engine details of the database entry were incomplete, and ship-type specific average values were used. In most of the cases shown in Fig. 3, the consumption of the auxiliary engines is overestimated, because the STEAM model uses a constant power value $(\mathrm{kW})$ for the auxiliary engines of all six RoPax cases regardless of their operation mode. The value depends on the installed auxiliary engine power, as described in Chapter 2.2.1. This feature could be improved by modelling the auxiliary engine use depending on, for example, ship size or by using ship-specific power profiles obtained from the shipowners.

An example of significant wave height is presented in Fig. 4, as predicted by the WAM model. The significant wave height varies on a scale of kilometres; there is a significant temporal variation on a scale of hours, too. An example of the predicted daily fuel consumption within a month is presented in Fig. 5 for one particular ship, with and without the effects of waves. There is only a minor difference between the two modelled consumptions. In this example, the difference can be seen only on a daily basis, but the smaller the time average considered the more pronounced the difference is between the two cases. Unfortunately, the lack of hourly and daily fuel consumption data for comparison from a large number of ships prevents drawing comprehensive conclusions about the effect of waves. For instance, if the data is neglected for the two days $\left(2^{\text {nd }}\right.$ and the $\left.20^{t h}\right)$, for which there are substantial gaps in the AIS data, the model predictions of the fuel consumption in October 2007 for RoPax 2 were within $3 \%$ and $6 \%$ of the reported values, without and with the wave effects, respectively. The comparisons of the fuel consumption can as well be made for specific voyages between ports, cf. Fig. 6. This example case illustrates the influence of short-lived and local effects due to waves. The voyage-specific main engine fuel consumption was reported by the shipowner as 44878 kilograms, while predictions with the estimated effect of waves was $44344 \mathrm{~kg}$ and without waves $38894 \mathrm{~kg}$. Such details are important, if the temporal or spatial resolutions are significantly increased.

On an inventory level for the whole of the Baltic Sea, the importance of the waves was negligible (0-2\%). However, for individual ships, the estimated increase of hourly fuel consumption can be as high as $10-20 \%$. It is not possible to draw more detailed conclusions regarding the significance of the effect of waves, before more hourly averaged and voyagespecific fuel consumption data is available. It is probably not necessary to include the effects of waves in ship emission inventories over extensive geographical areas. However, on a local scale or for individual ships, the effect of waves is not necessarily negligible. In the following, all emissions have been computed without the effects of waves, unless stated otherwise.

The specific fuel oil consumption (SFOC) depends on the engine type; two-stroke engines consume less (160$200 \mathrm{~g} / \mathrm{kWh}$ ) and four-stroke engines slightly more (180$250 \mathrm{~g} / \mathrm{kWh}$ ) (IMO, 2009) Changing the default SFOC of two stroke engines to $180 \mathrm{~g} / \mathrm{kWh}$ for new ships (built after 1 January 2001) decreased the monthly total fuel consumption in the Baltic Sea area by less than $2 \%$. Change of opposite sign will result for four-stroke engines and the net effect to the results reported in this study is likely to be negligible.

\subsection{Spatial and temporal distribution of annual total emissions}

On the basis of an analysis of a full year (2007) of AIS data, the computation of the emissions results in 400 kilotons of $\mathrm{NO}_{\mathrm{x}}$ emitted in the Baltic Sea area. This estimate of $400 \mathrm{kt}$ $\mathrm{NO}_{\mathrm{x}}$ is probably a lower limit, due to the various assumptions made in the modelling, such as the under-estimation of emissions from ships built before the year 2000, the neglecting of vessels that are not equipped with the AIS system and the assumption that all unidentified ships were small craft. The annual estimates for $\mathrm{SO}_{\mathrm{x}}\left(\right.$ as $\left.\mathrm{SO}_{2}\right)$ and $\mathrm{CO}_{2}$ emissions in 2007 were $138 \mathrm{kt}$ and $19 \mathrm{Mt}$, respectively. The estimated fuel consumption of Baltic Sea shipping in 2007 was $6205 \mathrm{kt}$, which corresponds to $265 \mathrm{PJ}$ of energy consumed; these can 


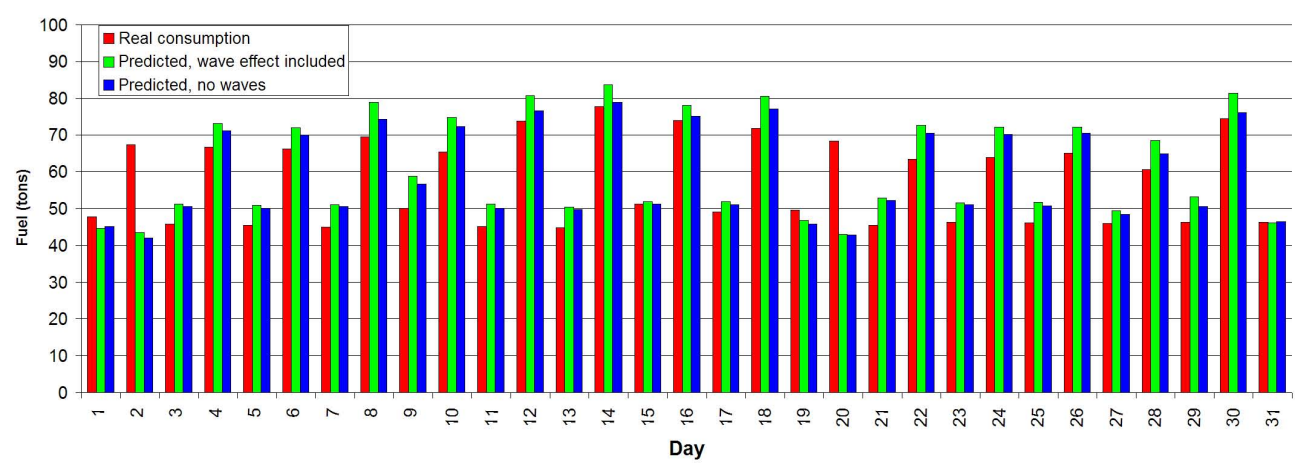

Fig. 5. Comparison of daily fuel consumption of the RoPax 2 ship (the same as in Fig. 3) with a gross tonnage of 58000 , in October 2007. The red bars show the fuel consumption as reported by the shipowner. The green and blue bars show the predicted fuel consumption with and without the effect of waves.

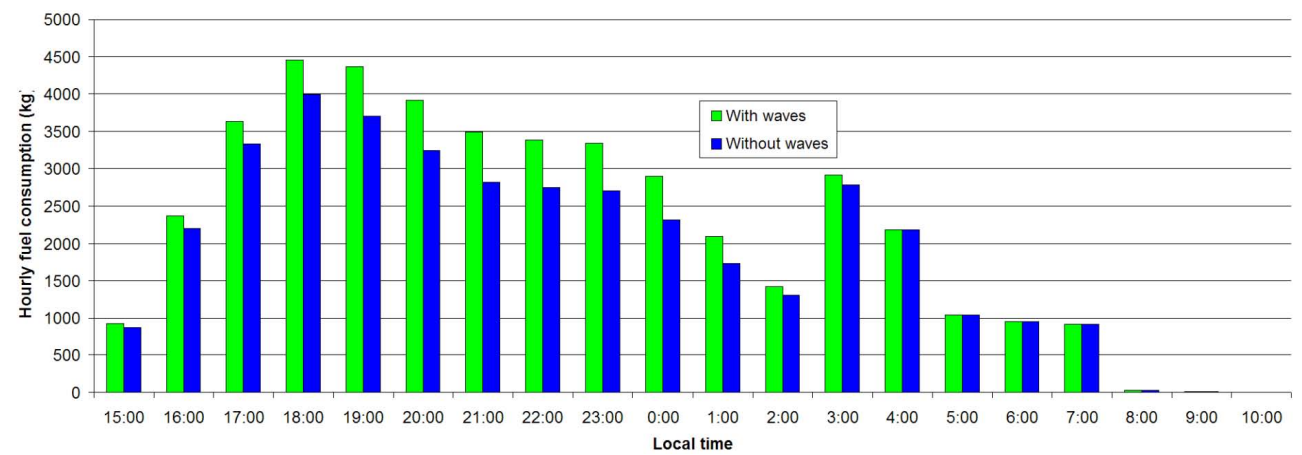

Fig. 6. Predicted hourly fuel consumption of the 58000 GT RoPax 2 ship during a single voyage in 8-9 October 2007.

be qualitatively compared with the $5301 \mathrm{kt}$ consumption and 215 PJ (Davies et al., 2000) projected for the year 2001.

The current estimates by EMEP of the $\mathrm{NO}_{\mathrm{x}}$ and $\mathrm{SO}_{\mathrm{x}}$ emissions in the Baltic Sea area were not available, but in 2006 these were reported as $346.7 \mathrm{kt}$ and $224.8 \mathrm{kt}$ (Vestreng et al., 2004). The estimate of this study for the annual $\mathrm{SO}_{\mathrm{x}}$ emissions (138 kt) is considerably lower. The Sulphur Emission Control Area limitations became effective in the Baltic Sea area on 19 May 2006, which set the sulphur cap of fuel to 1.5 mass-percentage instead of the global average of 2.7 masspercentage (Endresen et al., 2005). It has not been stated, whether the values reported by EMEP include the influences of this change or not (EMEP, 2006). The geographical distribution of annual $\mathrm{NO}_{\mathrm{x}}$ emissions from ships in 2007 is presented in Fig. 7, where the main fairways are easily recognizable. The largest fairway $\mathrm{NO}_{\mathrm{x}}$ emissions occur in the Southern Baltic, the Kiel Canal in Germany and in the Gulf of Finland, where emissions of over 500 tons/grid occur commonly. This corresponds to over $6.3 \mathrm{~g} / \mathrm{m}^{2}$ of $\mathrm{NO}_{\mathrm{x}}$ per year.

The the number of ships observed are highest during the summer months, which can be attributed to the increased passenger traffic during that period. During June, July and August of 2007 there were about 4500 ships traveling in the Baltic Sea, while during February the number was 3700 . The emissions of $\mathrm{NO}_{\mathrm{x}}$ and $\mathrm{SO}_{\mathrm{x}}$ are also highest during the summer months. The difference between the months with the highest (July) and lowest (February) predicted $\mathrm{NO}_{\mathrm{x}}$ emissions was $20 \%$ in the Baltic Sea area in 2007. Globally, the seasonal variation of emissions is smaller (Corbett et al., 1999).

\subsection{Classification of emissions by different categories}

Ship-specific inventories allow for the classification of emissions according to various categories. For example, the largest contribution to annual $\mathrm{NO}_{\mathrm{x}}(39 \%)$ and $\mathrm{SO}_{\mathrm{x}}(43 \%)$ was from new ships, classified in this study as those built after 1 January 2000.

According to Figure 9, one quarter of the $\mathrm{NO}_{\mathrm{x}}$ was emitted by ships built in the 1990's and almost one fifth by ships from the 1980's. The emissions of older ships are probably underestimated, as all ships are assumed to be in accordance with the IMO $\mathrm{NO}_{\mathrm{x}}$ curve, which has not, however, been a requirement for older ships. The ships in the three of the youngest groups constitute $60 \%$ of all the ships. The fourth age group is considerably smaller, referring to that the life cycle of a ship in the Baltic Sea area is around 30 years. 


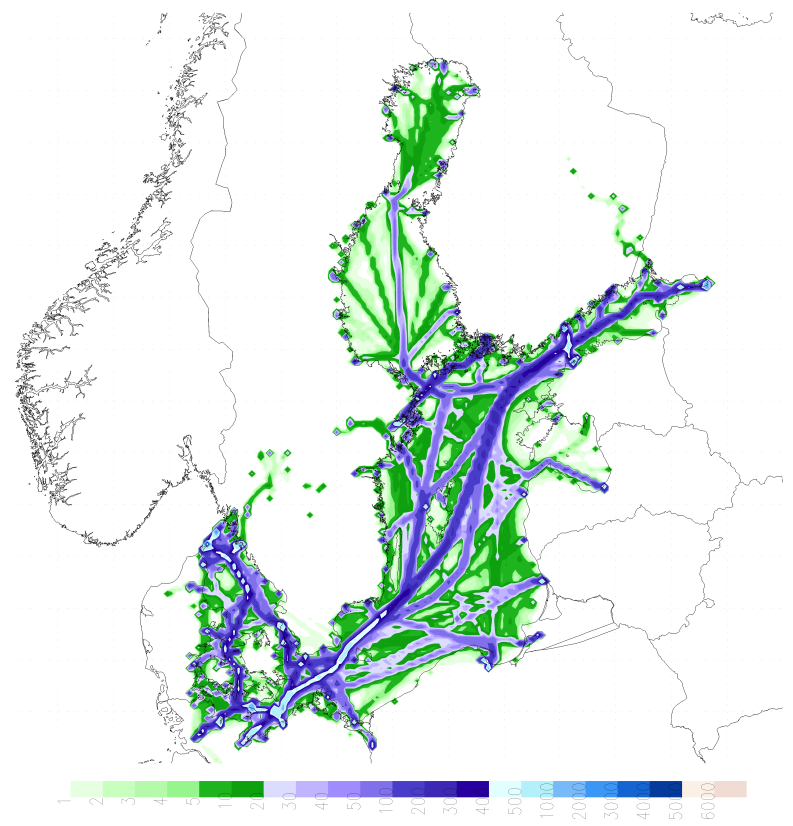

Fig. 7. Predicted annual sum of $\mathrm{NO}_{\mathrm{x}}$ emission $\left(\right.$ as $\left.\mathrm{NO}_{2}\right)$ due to Baltic Sea shipping in 2007. Emissions are given as tons/grid cell. The grid resolution is 0.08 degrees (approximately $9 \mathrm{~km}$ by $9 \mathrm{~km}$, rotated lon/lat grid). Emission values over 500 tons/cell $\left(6.3 \mathrm{~g} \mathrm{~m}^{-2}\right)$ occur commonly in the heavily-frequented fairways of the southern Baltic Sea and between Sweden and Denmark.

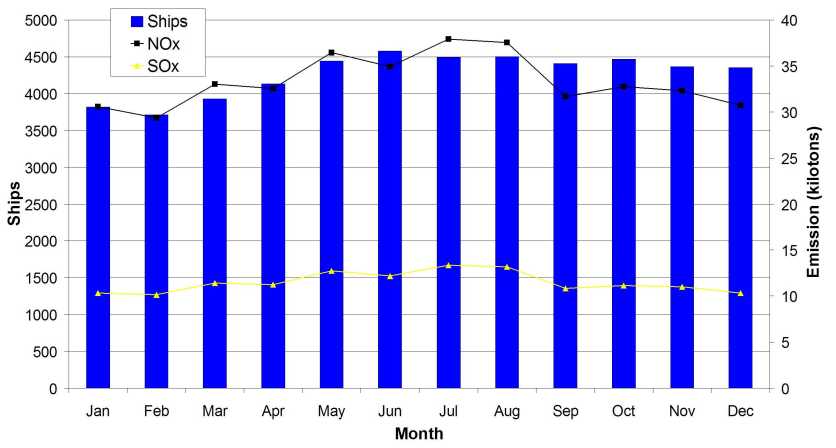

Fig. 8. The predicted seasonal variation of emissions of NOx and $\mathrm{SO}_{\mathrm{x}}$ from Baltic Sea shipping in 2007. The bars show the number of ships. The black line shows the monthly $\mathrm{NO}_{\mathrm{x}}$ emissions and the yellow line the $\mathrm{SO}_{\mathrm{x}}$ emission (in kilotons).

Classification of emissions in terms of the ship type shows that the exhaust emissions of certain types of ships are substantially higher than their relative proportion of all the ships. A comparison of the different ship types is presented in Fig. 10. The blue bar shows the percentage of ships in each type. The black, yellow and green bars show the relative emissions of $\mathrm{NO}_{\mathrm{x}}, \mathrm{SO}_{\mathrm{x}}$ and $\mathrm{CO}_{2}$, respectively. The columns describing the $\mathrm{SO}_{\mathrm{x}}$ and $\mathrm{CO}_{2}$ emissions are not in all cases equal. This is caused by the fact that some ships voluntarily use fuel, which contains less sulphur than what is dictated by the SECA regulations.

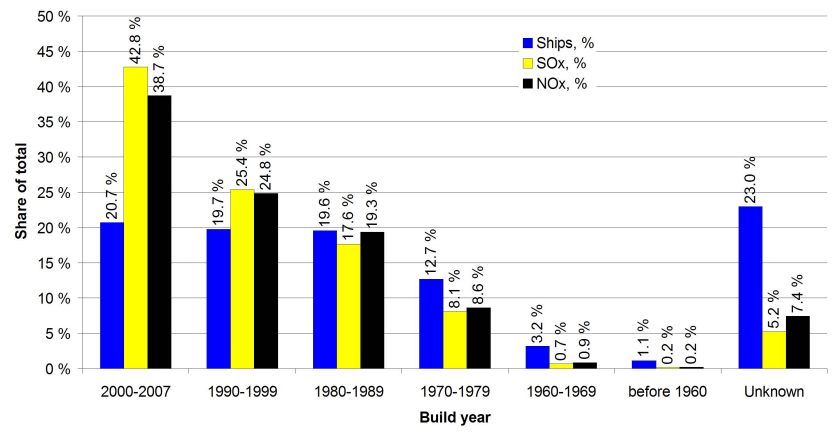

Fig. 9. Share of ships by age (blue) in the Baltic Sea area in 2007. The emission share of each age group of ships is shown with yellow $\left(\mathrm{SO}_{\mathrm{X}}\right)$ and black $\left(\mathrm{NO}_{\mathrm{X}}\right)$ bars

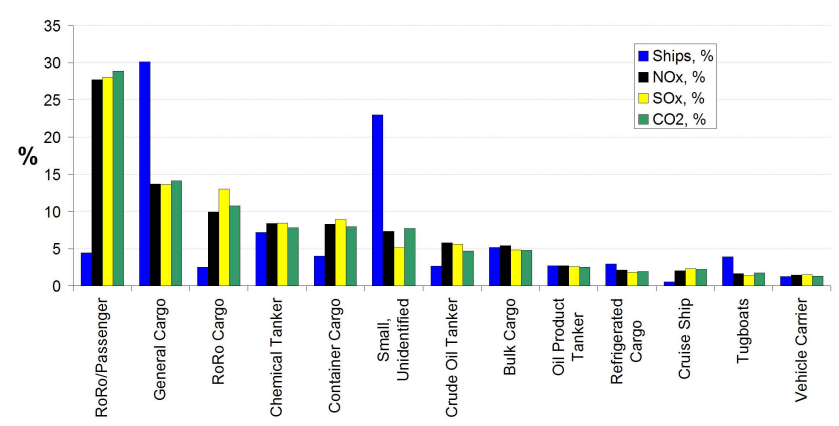

Fig. 10. Relative proportions of ship types and their emissions. Only ship types responsible for over $1 \%$ of $\mathrm{NO}_{\mathrm{x}}$ emissions are shown. These 13 types are responsible for $>96 \%$ of the total NOx generated by Baltic Sea shipping during 2007. The blue bar shows the proportion of ships in each category, black, yellow and green bars the proportion of $\mathrm{NO}_{\mathrm{x}}, \mathrm{SO}_{\mathrm{x}}$ and $\mathrm{CO}_{2}$ produced by each of the ship types.

While RoRo/Passenger ships (RoPax) represent less than $5 \%$ of all ships, their emission was over $25 \%$ of the total $\mathrm{NO}_{\mathrm{x}}, \mathrm{SO}_{\mathrm{x}}$ and $\mathrm{CO}_{2}$ in 2007. Emissions of container ships (8\%) are larger than their share of total number of ships (4\%). The study of De Meyer (De Meyer et al., 2008) showed that container ships are a significant source of air emissions, despite their small share of the total number of ships. Container ships and RoRo cargo/RoPax ships usually have large engines and work to a tight schedule. Pushing engines to their limits rapidly increases the fuel consumption and exhaust emissions. In the Baltic Sea the containership feeders are significantly smaller $(<1500 \mathrm{TEU})$ than the long distance container carriers which frequent the North Sea area and the English Channel. An interesting feature of the ship traffic in the Baltic Sea area is the heavy use of RoRo and RoPax ships, which are larger than the container feeder vessels. Evidently, if some ships travel significantly longer total distances than others, the emissions from these ships tend to be larger when presented as total emissions. For example, the average distance travelled by a RoPax in the Baltic Sea 


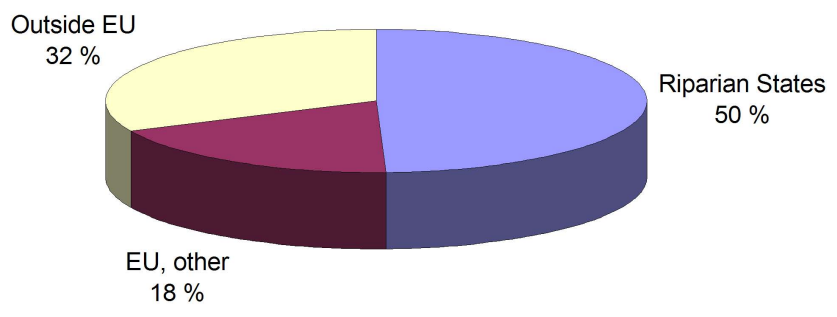

Fig. 11. $\mathrm{NO}_{\mathrm{x}}$ emission by flag state, 2007.

can be twice as large as an average container feeder. The specific emissions of $\mathrm{NO}_{\mathrm{x}}$ (i.e., emissions divided by the distance) from different ship types and age groups are presented in supplementary material II http://www.atmos-chem-phys. net/9/9209/2009/acp-9-9209-2009-supplement.pdf.

As can be seen from Figs. 9 and 10 and supplementary material II http://www.atmos-chem-phys.net/9/9209/ 2009/acp-9-9209-2009-supplement.pdf, ships belonging to the newest age group (marked as 2000) produce a significant portion of the emissions even if the traveled distances are taken into account. The values presented in supplementary material II http://www.atmos-chem-phys. net/9/9209/2009/acp-9-9209-2009-supplement.pdf $(\mathrm{kg} / \mathrm{km})$ are still affected by the size of the ships in each class, which may be an issue for most modern ships since nowadays larger ships are built on the average than a decade or two ago. Based on Fig. 10 and supplementary material II http://www.atmos-chem-phys.net/9/9209/ 2009/acp-9-9209-2009-supplement.pdf, RoPax ships and oil tankers have large emissions shares, but the total amount of cargo transported in RoPax vessels is lower than in crude oil tankers. Specific unit emissions $\left(\mathrm{g} \mathrm{ton}^{-1} \mathrm{~km}^{-1}\right.$ ) per the amount of cargo transported are bound to be higher for RoPax ships than for crude oil tankers, because the total cargo volume can be more efficiently used in crude oil tankers than in RoPax ships.

Classification of emissions in terms of the flag state was done based on the country codes of the Mobile Maritime Service Identity numbers (MMSI codes). Half of the $\mathrm{NO}_{\mathrm{x}}$ emissions originated from ships registered in the riparian states of the Baltic Sea (Fig. 11), almost one third came from ships registered to a country outside the European Union and the rest from ships in other EU member states.

A further division into individual flag states is given in Figure 12. The comparisons only show the flag state of the emission source. Nordic countries (except Iceland) are at the top of this list along with Germany. For instance, approximately $89 \%$ of export and $\sim 76 \%$ of import (in tons) in Finland takes place by sea (Finnish National Board of Customs, 2008). Almost all the major harbors of Sweden, Finland and Denmark are situated on the coast of the Baltic Sea, while Russia and Germany can extensively use harbours outside the Baltic Sea area. Of course, the shipowner can reside in one country, while the ship may sail under a different flag. This is particularly the case for ships sailing under a flag of convenience, such as those of Liberia, Bahamas and Panama. The flag state distribution of emissions has been mentioned as one of the mechanisms of emissions trading, but this may lead to a tonnage shift (IMO, 2009) towards countries with less rigorously regulated flags, unless such restrictions will be globally applied.

\section{Conclusions}

The objectives of this study were to develop flexible and versatile assessment tools for investigating the characteristics of shipping emissions. In addition to the temporal variations and geographical distribution of the shipping emissions, it is possible to classify them according to a variety of criteria. The model developed also makes it possible to study traffic flows in specific regions. The effects of waves can be included as well using information on the significant wave height in the study area. A finer spatial and temporal resolution can be used to study, for example, the detailed properties of shipping within harbours or in the vicinity of nature conservation areas. The spatial and temporal resolutions are limited only by the accuracy of the GPS equipment on board the ships.

Clearly, the STEAM model also has several inherent limitations. The information regarding the stack height has not yet been included as output data; this information has therefore to be evaluated separately in estimating the atmospheric transport of pollution originating from shipping. The model determines the $\mathrm{NO}_{\mathrm{x}}$ emission factors based on engine speed and the IMO $\mathrm{NO}_{\mathrm{x}}$ curve. This assumption was necessary to cope with the insufficient emission data for older engines. However, the use of this assumption may be inaccurate for older engines, those constructed prior to the year 2000, as these engines were not subject to the more stringent regulations of MARPOL Annex VI (IMO, 1997) in 2007. There are substantial uncertainties concerning the predicted power of the auxiliary engines, which significantly affect the emissions in harbor areas. Currently, no single information source can provide for all the input data required by the STEAM model; this encourages us to improve both the internal ship database and the STEAM model itself. For example, the details regarding the installed auxiliary engines, emission abatement techniques and shaft generators can be difficult to obtain otherwise than by directly contacting the shipowners.

Future development areas of the STEAM model include the effects of sea ice on thrust requirements, shallow water phenomena (squat), hull fouling or sea currents. All vessels are handled as single-propeller and single-hull ships; catamaran and trimaran structures or hydrofoil designs need to be modelled as well. These approximations probably have a negligible effect on the overall accuracy of the emission inventories, but they may substantially affect ship-specific 


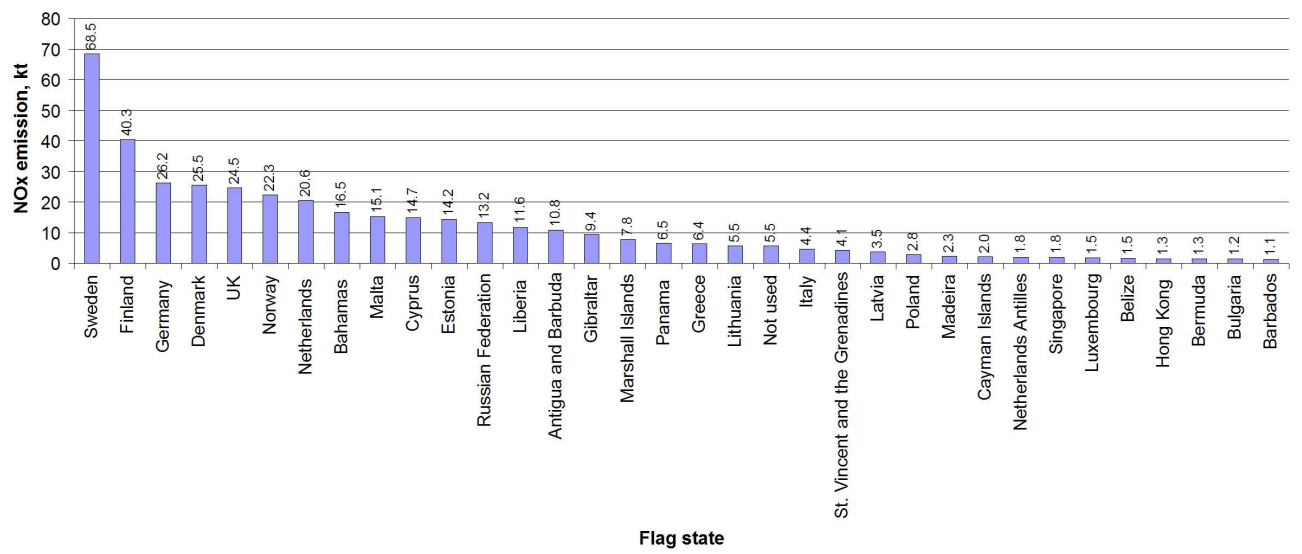

Fig. 12. $\mathrm{NO}_{\mathrm{x}}$ emission in the Baltic Sea area by flag state, breakdown by country, 2007. $\mathrm{NO}_{\mathrm{x}}$ emissions over 1 kiloton are shown, constituting approximately $99 \%$ of the total $\mathrm{NO}_{\mathrm{x}}$ emissions. The entry "Not used" indicates a country code that, according to the International Telecommunications Union, is not supposed to be used.

emissions. The STEAM model can treat mathematically short gaps of information in AIS data $(<72 \mathrm{~h})$; however, long-lasting gaps between position reports may lead to inaccurate predictions. In this study we have computed the numerical results neglecting the effect of waves, partly as experimental data is scarce for evaluating that section of the model. Non-AIS marine traffic should be included as a background source. However, it was not possible to evaluate the emissions of the smallest craft, except for Finland, due to lack of vessel movement data and missing statistics in many riparian countries. Obviously, including the effects of sea ice, waves and non-AIS traffic would increase the predicted values of emissions of $\mathrm{NO}_{\mathrm{x}}, \mathrm{SO}_{\mathrm{x}}$ and $\mathrm{CO}_{2}$, and that of fuel consumption, compared with the values reported in this paper.

The evaluations for the annual emissions of $\mathrm{NO}_{\mathrm{x}}, \mathrm{SO}_{\mathrm{x}}$ and $\mathrm{CO}_{2}$ without the effects of waves in the Baltic Sea area in 2007 were $400 \mathrm{kt}, 138 \mathrm{kt}$ and $19 \mathrm{Mt}$, respectively. The predicted fuel consumption of Baltic Sea shipping was $6205 \mathrm{kt}$, which corresponds to an energy consumption of 265 PJ. Half of the exhaust emissions arising from Baltic Sea shipping originated from vessels registered to a Baltic Sea riparian state.

The fuel consumption data provided by the shipowners is valuable for the model evaluation, but substantially more data is needed regarding the power profiles of various ship types during various operating modes. Direct emission measurements are required, especially for ships built before the year 2000. The AIS data-based computation of the ship emissions allows the determination of vessel-specific emission inventories. The emission data produced by the STEAM model can be used as input for studies of the regional and long-range transport of pollutants and their health effects and, e.g., in the evaluation of the effects of various emission abatement measures and policies, such as the construction of emissionbased fairway dues systems. The STEAM model presented in this study could be used to evaluate shipping emissions anywhere in the world as well, provided that the AIS data from that area were available and the relevant ship databases were up to date.

Acknowledgements. The authors would like to thank the Finnish Shipowners Association, the Finnish Maritime Administration, the Helsinki Commission (HELCOM) and Kari Mäkelä from the Technical Research Centre of Finland for assistance and cooperation. Many thanks also to Laura Tuomi and Marke Hongisto at FMI for wave data extraction and technical assistance. Support from Finnish Ministry of Transport and Communication, Finnish Maritime Administration, the Interreg IIIA program (ShipNODep project, FIMOS 113552) and the COST ES0602 action are gratefully acknowledged. The research leading to these results has also received funding from the European Community's Seventh Framework Programme FP/2007-2011 under grant agreement no 212520 .

Edited by: V.-M. Kerminen

\section{References}

Bewersdorff, I., Aulinger, A., Matthias, V., and Quante, M.: Modelling of Benzo(a)pyrene Depositions over North Sea Coastal Areas: Impact of Emissions from Local and Remote Areas, in Air Pollution Modelling and Its Application XIX - NATO Science for Peace and Security Series C, ISBN: 978-1-4020-8452-2, Springer, The Netherlands, 296, 296-304, 2008.

Capaldo, K., Corbett, J. J., Kasibhatla, P., Fischbeck, P., and Pandis, S. N.: Effects of ship emissions on sulphur cycling and radiative climate forcing over the ocean. Nature 400, 743-746, 1999.

Corbett, J. J., Fishbeck, P. S., Pandis, S. N. Global nitrogen and sulphur inventories for oceangoing ships. J. Geophys. Res., 104, 3457-3470, 1999.

Corbett, J. J. and Köhler, H. W.: Updated emissions from ocean shipping. J. Geophys. Res., 108(D20), 4650, doi:10.1029/2003JD003751, 2003. 
Corbett, J. J., Winebrake, J. J., Green, E. H., Kasibhatla, P., Eyring, V., and Lauer, A.: Mortality from Ship Emissions: A Global Assessment, Env. Sci. Tech., 41, 8512, doi:10.1021/es071686z, 2007.

Dalsøren, S. B., Endresen, Ø., Isaksen, I. S. A., Gravir, G., and Sørgård, E.: Environmental impacts of the expected increase in sea transportation, with a particular focus on oil and gas scenarios for Norway and northwest Russia. J. Geophys. Res., 112, D02310, doi:10.1029/2005JD006927, 2007

Davies, M. E., Plant, G., Cosslett, C., Harrop, O., Petts, J. W. Study on the economic, legal, environmental and practical implications of a European Union system to reduce ship emissions of $\mathrm{SO}_{2}$ and $\mathrm{NO}_{\mathrm{x}}$. Final report. BMT Murray Fenton Edon Liddiard Vince Limited, No. 3623, 56 pp., 2000.

Davis, D. D., Grodzinsky, G., Kasibhatla, P., Crawford, J., Chen, G., Liu, S., Bandy, A., Thornton, D., Guan, H., Sandholm, S. Impact of Ship Emissions on Marine Boundary Layer NOx and SO2 Distributions over the Pacific Basin, Geophys. Res. Lett., 28, 235-238, 2001.

De Meyer P, Maes F, Volckaert A. Emissions From International Shipping in the Belgian Part of the North Sea and the Belgian Seaports, Atm. Env., 42 , 196., doi:10.1016/j.atmosenv.2007.06.059, 2008.

DeMers, D., Walters, G. BAE Systems: Guide to Exhaust emission control options. International Council of Combustion Engines (CIMAC) report, 2000.

Dentener, F., Kinne, S., Bond, T., Boucher, O., Cofala, J., Generoso, S., Ginoux, P., Gong, S.,Hoelzemann, J.J., Ito, A., Marelli, L., Penner, J. E., Putaud, J.-P., Textor C., Schulz, M., van der Werf G. R., Wilson, J. Emissions of primary aerosol and precursor gases in the years 2000 and 1750 prescribed data-sets for AeroCom. Atmos. Chem. Phys. 6, 4321, 2006.

Dong, C., Huan, K.-L., Chen, C.-W., Lee, C.-W., Lin, H.-Y., Chen, C.-F. Estimation of Air Pollutants Emission from Shipping in the Kaohsiung Harbor Area. Aerosol and Air Quality Research, 2,31, 2002.

EMEP expert emissions, available online at: http: //webdab1.umweltbundesamt.at/cgi-bin/wedb2_controller. pl?State $=$ scaled $\&$ countries $=\% 3$ ASHIPS $\&$ years $=2006 \&$ sectors $=$ $1008 \&$ pollutants $=$ SOx $\&$ datatype $=$ national $\mathrm{html} \&$ horizontal $=$ area\&vertical=year\&info=on, 2006.

Endresen, Ø., Sørgård, E., Sundet, J. K., Dalsøren, S. B., Isaksen, I. S. A., Berglen, T. F., and Gravir, G.: Emission from international sea transportation and environmental impact, J. Geophys. Res., 108(D17), 4560, doi:10.1029/2002JD002898, 2003.

Endresen, Ø., Bakke, J., Sørgård, E., Berglen, T. F., and Holmvang, P.: Improved modelling of ship $\mathrm{SO}_{2}$ emissions - a fuel-based approach, Atmos. Environ., 39, 3621, doi:10.1016/j.atmosenv.2005.02.041, 2005.

Endresen, Ø., Sørgård, E., Lee Behrens, H., Brett, P. O., and Isaksen, I. S. A.: A historical reconstruction of ships' fuel consumption and emissions, J. Geophys. Res., 112, D12301, doi:10.1029/2006JD007630, 2007.

ENTEC UK Limited: Quantification of emissions from ships associated with ship movements between ports in the European Community, Final report to the European Commission, London UK, 2002.

Finnish National Board of Customs: Foreign trade transports, 2007, online available in Finnish at: http:
//www.tulli.fi/fi/05_Ulkomaankauppatilastot/11_Arkisto/

03_Tilastokatsaukset/2008/2008_M17.pdf

Georgakaki, A., Coffey, R. A., Lock, G., and Sorenson, S. C.: Transport and Environment Database System (TRENDS):Maritime air pollutant emission modelling, Atmos. Environ., 38, 2357, doi:10.1016/j.atmosenv.2004.07.038, 2005.

Greenhouse Gas Emissions for Shipping and Implementation Guidance for the Marine Fuel Sulphur Directive, Delft CE, Germanischer Lloyd, MARINTEK, Det Norske Veritas, Delft, The Netherlands, 2006.

International Maritime Organization: The International Convention for the Prevention of Marine Pollution from Ships, 1973 as modified by the Protocol of 1978 relating thereto (MARPOL 73/78), Annex VI: Prevention of Air Pollution from Ships, 1997 Amendments.

International Maritime Organization: Safety Of Life At Sea (SOLAS) agreement, regulation 19, Chapter V, 1974, 2002 Amendments.

International Maritime Organization: The International Convention for the Prevention of Marine Pollution from Ships, 1973 as modified by the Protocol of 1978 relating thereto (MARPOL 73/78), Annex VI: Prevention of Air Pollution from Ships, 2008 Amendments.

International Maritime Organization: The second IMO Greenhouse Gas study, UK, April 2009.

Isaksson, J., Persson, T. A., and Lindgren, E. S.: Identification and assessment of ship emissions and their effects in the harbour of Göteborg, Sweden, Atmos. Environ., 35, 3659-3666, 2001.

ITTC Recommended Procedures: ITTC Performance prediction method, 7.5-02-03-01.4, 1-31, 1999.

Kahma, K. K.: On Prediction of the Fetch-limited Wave Spectrum in a Steady Wind. Finnish Marine Research series, Finnish Institute of Marine Research, 253, 52-78, 1986.

Kesgin, U. and Vardar, N.: A study on exhaust gas emissions from ships in Turkish Straits. Atmos. Environ., 35, 1863-1870, 2001.

Komen, G. J., Cavaleri, L., Donelan, M., Hasselmann, K., Hasselmann, S., and Janssen, P. A. E. M.: Dynamics and modelling of ocean waves, Cambridge University Press, Cambridge, UK, 1994.

Lauer, A., Eyring, V., Hendricks, J., Jöckel, P., and Lohmann, U.: Global model simulations of the impact of ocean-going ships on aerosols, clouds, and the radiation budget, Atmos. Chem. Phys., 7, 5061-5079, 2007, http://www.atmos-chem-phys.net/7/5061/2007/.

Lloyd's Register - Fairplay Ltd, Lombard House, 3 Princess Way, Redhill, Surrey, RH1 1UP, UK, 2009.

Lövblad, G. and Fridell, E.: Experiences from use of some techniques to reduce emissions from ships, Swedish Maritime Administration, Göteborg, Sweden, 2006.

Marine Exhaust Emissions Quantification Study: Mediterranean Sea, Lloyd's Register London, UK, 99/EE/7044, 1999.

Mäkelä, K.: Calculation system for the Finnish waterway traffic emissions MEERI 2007, online available at: http://lipasto.vtt.fi/ meeri/index.htm, 2007.

Richter, A., Eyring, V., Burrows, J. P., Bovensmann, H., Lauer, A., Sierk, B., and Crutzen, P. J.: Satellite measurements of NO2 from international shipping emissions, Geophys. Res. Lett., 31, L23110, doi:10.1029/2004GL020822, 2004.

Service Contract on Ship Emissions: Assignment: Abatement and 
Market-based Instruments, Task 2, European Commission Directorate General Environment Report: Brussels, Belgium; ENTEC UK Limited, London, UK, 2005.

The Port of Los Angeles: Inventory of Air Emissions for Calendar Year 2007, Starcrest Consulting Group, Poulsbo, WA, USA, ADP\#050520-525, 2008.

Townsin, R. L., Kwon, Y. J., Baree, M. S., and Kim, D. Y.: Estimating the influence of weather on ship performance, RINA Transactions, 135, 1993.

Tuomi, L.: The accuracy of FIMR wave forecasts in 2002-2005. Meri : Report Series of the Finnish Institute of Marine Research, 63, 7-16, 2008.

Wahlström, J., Karvosenoja, N., and Porvari, P.: Ship Emissions and Technical Emission Reduction Potential in the Northern Baltic Sea, Reports of Finnish Environment Institute, 71 pp., August 2006.
Wang, C. and Corbett, J. J., Firestone, J. Modeling Energy Use and Emissions from North American Shipping: Application of the Ship Traffic, Energy, and Environment Model, Environ. Sci. Technol. 41, 3226, doi:10.1021/es060752e, 2007.

Wang, C., Corbett, J. J., and Firestone, J.: Improving Spatial Representation of Global Ship Emissions Inventories, Environ. Sci. Technol., 42, 193, doi:10.1021/es0700799, 2008.

Vestreng, V., Adams, M., and Goodwin, J.: Inventory Review 2004, Emission Data reported to CLRTAP and under the NEC Directive. EMEP/EEA Joint Review Report, EMEP/MSC-W Note 1/2004. ISSN: 0804-2446, 2004.

Yang, D.-Q., Kwan, S. H., Lu, T., Fu, Q.-Y., Cheng, J.-M., Streets, D. G., Wu, Y.-M., and Li, J.-J.: An Emission Inventory of Marine Vessels in Shanghai in 2003. Env. Sci. Tech. 41, 5183, doi:10.1021/es061979c, 2007. 